\title{
Child cortisol moderates the association between family routines and emotion regulation in low-income children
}

\author{
Alison L. Miller ${ }^{1,2 *}$ ～Ju-Hyun Song ${ }^{1,3} \quad$ | Julie Sturza ${ }^{1} \quad$ Julie C. Lumeng ${ }^{1,4,5}$ | \\ Katherine Rosenblum $^{1,6}$ | Niko Kaciroti ${ }^{1,7}$ | Delia M. Vazquez ${ }^{1,5,6}$
}

${ }^{1}$ Center for Human Growth and Development, University of Michigan, Ann Arbor, Michigan

2 Department of Health Behavior and Health Education, University of Michigan School of Public Health, Ann Arbor, Michigan

${ }^{3}$ Department of Psychology, University of Toronto, Toronto, Ontario, Canada

${ }^{4}$ Department of Nutritional Sciences, University of Michigan School of Public Health, Ann Arbor, Michigan

${ }^{5}$ Department of Pediatrics, University of Michigan Medical School, Ann Arbor, Michigan

${ }^{6}$ Department of Psychiatry, University of Michigan Medical School, Ann Arbor, Michigan

7 Department of Biostatistics, University of Michigan School of Public Health, Ann Arbor, Michigan

\section{${ }^{*}$ Correspondence}

Alison L. Miller, Center for Human Growth and Development, The University of Michigan, 300 North Ingalls, 10th Floor, Ann Arbor,

MI 48109-0406.

Email: alimill@umich.edu

Funding Information

This research was supported by National Institutes of Health (NIH) RC1DK086376.

\begin{abstract}
Biological and social influences both shape emotion regulation. In 380 low-income children, we tested whether biological stress profile (cortisol) moderated the association among positive and negative home environment factors (routines; chaos) and emotion regulation (negative lability; positive regulation). Children ( $M$ age $=50.6, S D=6.4$ months) provided saliva samples to assess diurnal cortisol parameters across 3 days. Parents reported on home environment and child emotion regulation. Structural equation modeling was used to test whether cortisol parameters moderated associations between home environment and child emotion regulation. Results showed that home chaos was negatively associated with emotion regulation outcomes; cortisol did not moderate the association. Child cortisol level moderated the routines-emotion regulation association such that lack of routine was most strongly associated with poor emotion regulation among children with lower cortisol output. Findings suggest that underlying child stress biology may shape response to environmental influences.
\end{abstract}

KEYWORDS

diurnal cortisol, home chaos, family routine, emotion regulation

\section{1 | INTRODUCTION}

Emotion regulation is a central developmental task of early childhood (Cole, Martin, \& Dennis, 2004). Effective emotion regulation skills encompass strategies both to reduce negative affect and to engage in positive interaction. As such, effective emotion regulation in children includes the abilities to calm down when upset, to understand and verbalize one's own and others' emotional states, and to express emotions in a contextually appropriate manner. Emotion regulation is influenced by interactions with the external social environment and internal child factors such as physiological processes that can shape how a child responds to such interactions (Perry, Mackler, Calkins, \& Keane, 2014). Children who develop in poverty can experience caregiving challenges and early life stress exposure, and as a group are at risk for emotion regulation difficulties (Evans \& English, 2002; Hardaway,
Wilson, Shaw, \& Dishion, 2012; Kim et al., 2013; Shonkoff et al., 2012). Yet, not all children who grow up in poverty experience emotion regulation problems. The current study tests how environmental and biological factors relate to individual differences in emotion regulation outcomes among low-income preschool-aged children. Specifically, we examine whether child diurnal cortisol parameters moderate associations between positive and negative home environment factors and child positive and negative emotion regulation outcomes.

\section{2 | BIOLOGICAL STRESS REGULATION AND CHILD EMOTION REGULATION}

The limbic-hypothalamic-pituitary-adrenal (LHPA) axis is a primary driver of the biological stress response. Under typical conditions, the 
LHPA axis is activated and causes the release of cortisol so that an individual can actively respond to stress and then recover back to a resting baseline as a result of feedback loops that alert the system to stop producing cortisol when the stress has passed (Gunnar \& Vazquez, 2001). Cortisol also follows a strong diurnal circadian pattern, marked by an early morning peak that activates the organism to "get going" for the day and subsequent decline, reaching a nadir in the evening hours and clearing cortisol from the system in preparation for sleep (Buckley \& Schatzberg, 2005). Early-life exposure to stress can have lasting effects on LHPA axis functioning, based on the idea that exposure to frequent stressors early in development can interrupt the negative feedback loops that are used to keep this stress-response system well-regulated (Miller, Chen, \& Parker, 2011). Specifically, chronic stress exposure can impair the ability of the LHPA axis to recover from stress and over time, may disrupt the diurnal pattern of cortisol secretion, resulting in atypical patterns such as lowered morning and elevated evening cortisol levels, with potentially negative health implications (Chrousos \& Gold, 1992; Miller, Chen, \& Zhou, 2007; Nicolaides, Kyratzi, Lamprokostopoulou, Chrousos, \& Charmandari, 2015)

Biological profiles characterized by low morning cortisol levels and blunted cortisol responses to stress have been found in populations experiencing chronic stress (Gunnar \& Vazquez, 2001; Heim, Ehlert, \& Hellhammer, 2000). This low morning/blunted stress response pattern of cortisol secretion has been increasingly seen in association with significant adverse life events and stress exposure (e.g., foster care placement) in children (Bernard, Butzin-Dozier, Rittenhouse, \& Dozier, 2010; Bruce, Fisher, Pears, \& Levine, 2009; Kushner, Barrios, Smith, \& Dougherty, 2015). It has been suggested that for young children living in chronically stressful family circumstances, attenuated cortisol responses may be adaptive in the short term as they may reduce the overall level of cortisol produced when it is not possible to escape the situation. However, such a pattern could incur long-term physiological costs, and therefore be maladaptive later in development if an individual becomes unable to mount an appropriate cortisol response (Miller et al., 2011). Thus, low cortisol levels in young children can be understood as an early marker of risk and may signal high allostatic load that could negatively affect later psychosocial functioning (Badanes, Watamura, \& Hankin, 2011). In preschoolaged samples, cumulative risks and poverty (Bernard, Hostinar, \& Dozier, 2015a; Bernard, Zwerling, \& Dozier, 2015b), insensitive parenting (Blair, Raver, Granger, Mills-Koonce, \& Hibel, 2011; Suor, Sturge-Apple, Davies, Cicchetti, \& Manning, 2015; Zalewski, Lengua, Kiff, \& Fisher, 2012), and family financial strain (Badanes et al., 2011) have been found to associate with low morning cortisol levels, flatter diurnal cortisol slopes, and blunted reactivity to stress.

How strongly emotions are aroused and how well they are managed under challenge are essential components of emotion regulation. Peer social interactions are a highly salient context for the development of emotion regulation skills during the preschool years, as they present many social challenges. A child's LHPA axis functioning may, therefore, influence emotion regulation outcomes by shaping how the child responds to such challenges. Children who are physiologically under-aroused may seek stimulation and therefore act out impulsively in social contexts (van Goozen, Fairchild, Snoek, \& Harold, 2007), whereas children who are over-aroused may have difficulty controlling emotional outbursts. Such behaviors may result in negative peer interactions and over time, impair psychosocial functioning if emotions and behaviors are not well-managed (KimSpoon, Cicchetti, \& Rogosch, 2013). Findings regarding cortisol, emotions, and psychosocial outcomes in children are somewhat mixed, with evidence for associations of both lower cortisol and higher cortisol with behavior problems over time (Gunnar \& Vazquez, 2006) possibly through different pathways (Strüber, Strüber, \& Roth, 2014). In middle-income preschool-aged children, flatter diurnal cortisol profiles in the context of peer conflict have been found among children with a history of maltreatment, whereas higher cortisol levels in peer conflict contexts were associated with greater social competence among all children (Hart, Gunnar, \& Cicchetti, 1995). Other work has found higher cortisol levels among temperamentally surgent children who are actively engaged with getting to know new peers (Gunnar, Tout, de Haan, Pierce, \& Stansbury, 1997). Although not conclusive, findings suggest that cortisol activation may be important in helping a child navigate social challenges in an adaptive manner, whereas lower cortisol levels may indicate lack of engagement, under-arousal, or high allostatic load, with possible links to poorer subsequent psychosocial functioning (Badanes et al., 2011; Tyrka et al., 2012).

A moderate, versus blunted, level of reactivity in the LHPA system in response to challenge has also been associated with better cognitive functioning and self-regulation, skills that are important for regulating emotional responses (Blair, Granger, \& Peters Razza, 2005). Cortisol may be needed to up-regulate the organism's hormonal responses to effectively manage cognitive, social, and emotional challenges (Blair et al., 2005; Erickson, Drevets, \& Schulkin, 2003). As cognitive reappraisal and attentional refocusing skills are central features of effective emotion regulation strategies (Gross \& John, 2003), blunted cortisol may limit a child's capacity to engage in such strategies. Failure to produce an early morning cortisol peak in particular may hinder a child's ability to mobilize energy and activate receptors on specific brain regions that are essential for exploration and learning consolidation (de Kloet, Oitzl, \& Joels, 1999). Taken together, biological stress regulation, perhaps specifically low-cortisol production, may be associated with poorer overall emotion regulation in children, both with regard to the capacity to engage cognitive strategies to manage emotions and behavioral manifestations of poorly controlled emotion expression.

\section{3 | CORTISOL AS A MODERATOR OF ENVIRONMENTAL INFLUENCES}

Although early life stress is generally associated with poorer child outcomes, not all children are similarly affected. Developmental psychopathology frameworks suggest that biological factors shape the way children respond to environmental stressors, with implications for later adjustment (Gunnar \& Vazquez, 2006; Zuckerman, 1999). Prior work testing such diathesis-stress models has found that child 
biological stress response interacts with exposure to harsh environments to predict dysfunction. One such study in a community-based sample of preschool-aged children tested cortisol reactivity to challenge as a moderator of associations between stressful life events and behavior problems and found associations of stressful life events and externalizing symptoms among children who showed blunted cortisol responses to challenge, but no association for children with higher cortisol reactivity (Kushner et al., 2015). Among low-income preschoolers, children with more blunted diurnal cortisol patterns had more internalizing symptoms when they experienced stressors (Badanes et al., 2011). Another study examining diurnal cortisol pattern as a moderator of associations between parent depressive symptomatology and child behavior problems found that as parents' depressive symptoms increased, child internalizing and externalizing symptoms increased only among children with elevated evening cortisol levels (Laurent et al., 2013). Findings suggest cortisol may moderate associations between environmental risk factors and child social-emotional outcomes. Yet, limited work has considered environmental supports as well as adversity in relation to cortisol or assessed child outcomes along a continuum ranging from dysfunction to competence, not just dysfunction or its absence. Therefore, an additional goal of the current study was to examine positive and negative aspects of the home environment in relation to positive and negative child emotion regulation outcomes, and to test whether child cortisol moderated these associations.

\section{4 | TWO ASPECTS OF THE HOME ENVIRONMENT: CHAOS AND ROUTINE}

Instability is a hallmark of poverty that can create stress for young children, who thrive under structured and stable conditions (Ackerman \& Brown, 2010; Osborne \& McLanahan, 2007). Families who struggle financially often have unpredictable incomes and work schedules (or are unemployed), and may experience residential instability. Such circumstances can lead to environmental chaos in the home, including household crowding (e.g., many people to a bedroom), presence of disorder, and high noise levels (Evans \& English, 2002). Particularly during early childhood, environmental chaos has been associated with impairments in child mental and general physical health (Chen, Cohen, \& Miller, 2010; Coley, Lynch, \& Kull, 2015; Deater-Deckard et al., 2009). Chaos at home has also been associated with emotion regulation difficulties in children (Fiese \& Winter, 2010; Hardaway et al., 2012).

The mere absence of home chaos may not be enough to be protective for children, however, particularly children with altered stress biology. Parents are powerful regulators of child stress responses and formative influences on early emotion regulation, with much of this influence operating through parent-child interactions. Family routines, which are characterized by regularly occurring, predictable, and comforting interactions with a parent or caregiver (Spagnola \& Fiese, 2007), can serve as a foundational structure for healthy child development. Routines have been proposed as a mechanism that supports early childhood emotion regulation (Bridley \& Jordan, 2012; Ferretti \& Bub, 2014; Zajicek-Farber, Mayer, $\&$ Daughtery, 2012) as well as general well-being and health (Anderson \& Whitaker, 2010; Henderson, Barry, Bader, \& Jordan, 2011). Yet, routines may not have the same effect for all children in part due to individual differences (Spagnola \& Fiese, 2007; Wilson et al., 2014). Child factors such as difficult temperament (Churchill \& Stoneman, 2004; Spagnola \& Fiese, 2007; Wilson et al., 2014) or sex (Churchill \& Stoneman, 2004; Ferretti \& Bub, 2014) may drive the ease of establishing routines and also the effectiveness of routines in promoting positive outcomes. Given that children with high temperamental difficulty or poorly regulated psychobiology are at risk for developing maladaptive parent-child interaction patterns over time (Spagnola \& Fiese, 2007; Sprunger, Boyce, \& Gaines, 1985), such children may also be most in need of family routines. The current study therefore examines child cortisol as a moderator of response to both positive (i.e., routines) and negative (i.e., chaos) home environmental inputs among low-income preschool-aged children.

\section{5 | AIMS AND HYPOTHESES}

The aim of the current study was to test whether child cortisol moderated the association of positive and negative home environment factors and emotion regulation outcomes in a sample of preschool-age children from low-income families. We tested cortisol (morning level and decline across the day) as a moderator of the association between home environment and child emotion regulation. In each model, we considered negative as well as positive home environment factors (i.e., chaos, routine), and negative as well as positive aspects of child emotion regulation (i.e., negative lability, positive regulation capacity). We hypothesized that there would be main effects of home environment on child cortisol and emotion regulation such that more chaotic home environment and infrequent routines would relate to lower morning cortisol levels and flatter declines across the day, higher negative lability, and lower positive regulation. We also hypothesized that lower morning cortisol level and flatter decline across the day would associate with higher negative lability and lower positive regulation. We further hypothesized a moderating role of cortisol such that the associations between home environment factors and emotion regulation outcomes would be stronger for children with lower morning cortisol levels and flatter declines across the day compared to children with higher morning cortisol levels and steeper declines across the day.

\section{6 | METHODS}

\section{1 | Participants}

Participants were 380 preschool-aged children in the Midwest United States who were attending Head Start, which is a free, federally funded preschool program for low-income children. Children and their primary 
caregiver/legal guardian (referred to henceforth as "parent") were recruited through "backpack mail" at Head Start; parents were asked to complete and return a demographic form and were compensated $\$ 10$ for returning the form and providing contact information. After this, parents were contacted to assess whether they would be interested and eligible to participate. Exclusion criteria were as follows: parent with >4 year college degree; parent or child not English-speaking; child in foster care, with food allergies, significant medical problems, or perinatal complications, gestational age $<35$ weeks, or use of medication known or hypothesized to affect cortisol. The study was approved by the University [blinded] Institutional Review Board.

Children were an average of 50.6 months old $(S D=6.4) ; 50 \%$ were male. Regarding race/ethnicity, $56 \%$ of children were non-Hispanic White; $15 \%$ were African-American; $11 \%$ were Hispanic/Latino; and $17 \%$ were Biracial/Other (1\% Asian or Native American). Of parents, $35 \%$ were single parents; $16 \%$ did not graduate from high school, $24 \%$ had a high school degree, $8 \%$ had a Generalized Equivalency Diploma (GED), $40 \%$ had taken some college courses, and $12 \%$ had a 2 -year college degree. A study inclusion criterion was that the family was enrolled in Head Start and the poverty threshold was $\$ 21,954 /$ year$\$ 23,021$ /year for a family of four between 2009 and 2011, when the data were collected (https://aspe.hhs.gov/2009-hhs-povertyguidelines; retrieved February 10, 2016). Mean family income-toneeds ratio was $.87(S D=.77)$, confirming the sample was low-income.

Missing data were handled with full information maximum likelihood (FIML) estimation in structural equation modeling, resulting in 380 children for analyses. Among the 380 children, missing data percentages for study variables ranged from $0 \%$ to $3 \%$. The result of Little's Chi-Square Test of MCAR, $\chi^{2}(17)=13.41, p=.71$, implied that the data were missing completely at random (Little, 1988).

\section{$6.2 \mid$ Procedure}

Parents provided written informed consent and age appropriate assent was obtained from children; families were compensated for their time. Bachelors-level research assistants administered all questionnaires individually to parents and collected saliva samples from children. Details are described below.

\section{3 | Cortisol measures}

\subsection{1 | Cortisol}

To assess cortisol, saliva samples were gathered by the research assistants on three weekdays, three times per day (on arrival to preschool, before breakfast, about 8:30 am; before lunch, about $11 \mathrm{am}$; and about 3:30 pm). Children provided the samples by chewing on a braided cotton dental roll until saturated (passive drool methods were used for the six children who did not wish to chew on the cotton; $1.6 \%$ of the sample). Parents reported for each sample day whether the child had used any medication, was ill (fever, vomiting), whether it had been an unusually good or bad day, as well as the time the child woke that day and whether it was the usual time. Parents (or Head Start teachers as appropriate) were also asked whether the child had napped or eaten prior to each saliva sample. All saliva samples were stored at $-20^{\circ} \mathrm{C}$ until extracted and assayed for cortisol in duplicate using an Expanded Range High Sensitivity Salivary Cortisol Enzyme Immunoassay Kit (Salimetrics LLC, Carlsbad, CA) with a detection limit of $.003 \mu \mathrm{g} / \mathrm{dl}$. Inter-assay coefficient of variation was $5.5 \%$ and intraassay coefficient of variation was $4.6 \%$.

Data cleaning for cortisol values were as follows: values were excluded if the child had taken a medication known to affect cortisol on the sampling day; if the values were $>3 S D$ 's from the sample mean for that timepoint; or if values were $>2 S D$ 's from the sample mean and an unusual circumstance or event was reported (e.g., child had the flu). Only 66 of the 3,010 samples assayed (2.2\%) were excluded for the above reasons. Children who had at least five valid cortisol points across at least 2 days were included in the analysis (mean number of data points per child $=8.4, S D=1.2$ ).

The saliva sample was collected in the morning at a mean of $1.5 \mathrm{hr}$ $(S D=.6)$ after awakening, before lunch at a mean of $3.9 \mathrm{hr}(S D=.6)$ after awakening, and in the afternoon at a mean of $8.5 \mathrm{hr}(S D=.8)$ after awakening. Collection log data (i.e., medication use, illness, unusually good or bad events, exact time of morning awakening and if it was the usual time, napping or eating prior to saliva sampling) were not associated with cortisol diurnal pattern and were thus not used as covariates.

\section{4 | Questionnaire measures}

Parents completed a series of questionnaires to assess demographic covariates, home environment (chaos and routine), and child emotion regulation (negative lability and positive regulation).

\subsection{1 | Demographic covariates}

Parents reported children's sex, birthdate (from which age at assessment was calculated), race/ethnicity (categorized for this report as non-Hispanic White vs. not), primary caregiver education (high school graduate or less vs. more than high school), and family structure (single parent vs. not).

\subsection{2 | Home environment}

Parents completed the 15-item Chaos, Hubbub, and Order Scale (CHAOS) (Matheny, Wachs, Ludwig, \& Phillips, 1995) to assess the level of general chaos in the home. Parents responded to a series of statements to indicate whether the statement is true or false for their home environment (e.g., "There is often a fuss going on at our home"; "You can't hear yourself think in our home"). Items were summed to create a total score where a higher score indicates greater home chaos (Cronbach's alpha $=.80$ ). Parents completed the 14 -item Child Routines Inventory (Jordan, 2003) to assess how regularly the child engaged in family routines that involve interaction with or supervision by a parent (e.g., eating together; spending time reading/talking with parent; doing the same activities prior to bedtime; getting ready in the morning; saying good bye; completing age-appropriate chores), on a 5-point scale (from $0=$ "never" to 4 = "nearly always"). The sum of responses was calculated to generate a summary routines scale where higher scores indicate greater presence of routines (Cronbach's alpha $=.70$ ). 


\subsection{3 | Emotion regulation}

The 24-item Emotion Regulation Checklist [ERC; Shields and Cicchetti (1997)] was used to assess two aspects of child emotion regulation. Parents rated on a 4-point scale how characteristic each item was of their child. The Negative Lability subscale reflects the intensity of the child's anger and other negative emotions (16 items; e.g., "is easily frustrated", Cronbach's alpha $=.82$ ). The Positive Regulation subscale reflects the child's ability to understand others' emotional states, show empathy, and use words versus actions to express emotions (7 items, e.g., "can say when he or she is feeling sad, mad, or afraid"; Cronbach's alpha $=.64$ ). [One ERC item was deleted due to ambiguous wording as in prior work (Miller et al., 2006).] Higher scores reflect greater endorsement of each construct.

\section{5 | Analytic strategy}

Given that diurnal cortisol output follows a documented pattern where cortisol increases after morning awakening, reaching a peak usually within the first $30 \mathrm{~min}$ and afterwards decaying exponentially across the day, we used hierarchical linear modeling (HLM) to generate random parameters to capture individual diurnal cortisol curves for each participant using the restricted maximum likelihood method (REML) as in prior work (Lumeng et al., 2014). The HLM approach is a powerful modeling technique for estimating individual trajectories, provided that trajectories have a known parametric form (e.g. linear, log-linear, quadratic) (Hruschka, Kohrt, \& Worthman, 2005) and it can account for the time differential in the measurement of cortisol when sampling times are not identical, in a direct way using the parametric function of the known diurnal cortisol pattern. Using log-transformed cortisol as the outcome and the number of minutes since waking as the independent variable, the diurnal cortisol pattern is linear on time in a log-scale (for time $\geq 60 \mathrm{~min}$ ) and can be captured by two parameters, intercept and slope. In the current study, we therefore used HLM with random intercept and slope on log-transformed cortisol values as the outcome and the number of minutes since waking at the time of sample collection as the independent variable to estimate the random intercept and random slope. The random intercept is an estimate of the expected cortisol level at $60 \mathrm{~min}$ after awakening for a given individual, and the random slope is the expected rate of decay of cortisol after 60 min post-awakening, and together they capture the diurnal cortisol pattern of an individual. We ran the model testing whether sample day contributed to the prediction, and it did not $(p=.42)$, so we did not include day as a predictor in the HLM model. Each cortisol sample for each day is included in the model with the corresponding time since waking based on wake up time that particular day, and time that sample was taken. Random effect parameters thus estimated the child's expected cortisol pattern over the three sample days. The random intercept and slope estimates from the HLM analysis were then used as individual-level predictor variables for all subsequent analyses predicting negative lability and positive regulation.

We ran descriptive statistics and bivariate correlations to describe the sample in terms of predictor and outcome variables. We examined the two indicators of diurnal cortisol pattern, intercept (morning cortisol level) and slope (rate of decline across the day) as moderators of the association between the two home environment factors and the two emotion regulation outcomes. A set of path models was tested to examine these cortisol variables as moderators of the association between each positive and negative home environment factor and emotion regulation outcomes. For all analyses, structural equation modeling (SEM) was conducted using AMOS 22 (Arbuckle, 2013) to allow simultaneous estimation of covariance between the predictors and between the dependent variables. Model fit was assessed with the comparative fit index (CFI) and the root mean square of approximation (RMSEA). CFI greater than .90 indicates reasonably good fit and RMSEA less than .05 with upper bounds not exceeding .10 indicates close fit (Hu \& Bentler, 1999). We ran two separate SEM models, one with family routine as a positive environmental factor and the other with home chaos as a negative environmental factor predicting child emotion regulation outcomes. Children's negative lability and positive regulation were entered simultaneously as dependent variables for each model and were allowed to covary. Children's age, sex, and race/ ethnicity (non-Hispanic White vs. not), maternal education (high school graduate or less vs. more than high school), and family structure (single parent vs. not) were included as covariates in both models. We followed the analytic strategy used in prior work (Morgan, Shaw, \& Olino, 2012) which tested interactions between a child factor and two types of environments in predicting two types of outcomes. We created 2-way interaction terms (e.g., cortisol intercept $\times$ home chaos) by multiplying one cortisol factor (i.e., morning cortisol intercept, cortisol slope) and one environmental factor (i.e., home chaos, family routine) after centering them. Significant 2-way interactions were explored following recommendations (Aiken, West, \& Reno, 1991) for testing and plotting simple slopes at $1 S D$ below (low) and $1 S D$ above (high) the mean of the moderating variable (i.e., morning cortisol intercept or cortisol slope).

\section{7 | RESULTS}

\section{1 | Descriptive statistics and bivariate correlations}

We conducted descriptive statistics and examined zero-order correlations among all study variables (Table 1). Lower morning cortisol intercept was associated with more home chaos and higher child negative lability. More regular routines were related to less child negative lability and greater positive regulation. Higher chaos was related to higher negative lability and lower positive regulation. Finally, routines and chaos were inversely associated, as were negative lability and positive regulation. Among the demographic variables, child age was positively related to positive regulation, mothers' education was positively related to positive regulation and inversely related to negative lability, and single-parent status was related to higher morning cortisol intercept.

\section{2 | Descriptive analysis of cortisol pattern}

Figure 1 presents the overall cortisol pattern for the sample, with values representing the estimated cortisol level at $1 \mathrm{hr}$ since waking 
TABLE 1 Descriptive statistics and bivariate correlations among study variables $(n=380)$

\begin{tabular}{|c|c|c|c|c|c|c|c|c|c|c|c|}
\hline & 1 & 2 & 3 & 4 & 5 & 6 & 7 & 8 & 9 & 10 & $M(S D)$ or $N(\%)$ \\
\hline 1. Child age & & & & & & & & & & & $50.64(6.35)$ \\
\hline 2. Child sex & -.01 & & & & & & & & & & 190 (50\%) male \\
\hline 4. Maternal education & .08 & -.07 & -.09 & & & & & & & & $\begin{array}{l}184(48.4 \%) \leq \text { high } \\
\text { school }\end{array}$ \\
\hline $\begin{array}{l}\text { 6. Morning cortisol } \\
\text { intercept }\end{array}$ & -.10 & -.06 & .10 & .02 & $.11^{*}$ & & & & & & $.19(.07) \mu \mathrm{g} / \mathrm{dl}$ \\
\hline 7. Cortisol slope & -.09 & .04 & -.06 & -.02 & -.09 & $.20^{* *}$ & & & & & $-.07(.03) \mu \mathrm{g} / \mathrm{dl} / \mathrm{hr}$ \\
\hline 8. Routine & -.01 & -.02 & -.004 & .04 & -.09 & .01 & .05 & & & & $45.46(6.18)$ \\
\hline
\end{tabular}

Cortisol slope and intercept are both estimated. Child sex $1=$ boy, $2=$ girl; child race/ethnicity $0=$ non-Hispanic White, $1=$ others; maternal education $0=$ high school graduate or less, $1=$ more than high school; family structure $0=$ single parent, $1=$ non-single parent; $N$ and $\%$ are reported for these categorical variables.

$\%$ are reported for these categorical variables.

${ }^{*} p<.05,{ }^{* *} p<.01$.

(morning sample), $4 \mathrm{hr}$ since waking (midday sample), and $8 \mathrm{hr}$ since waking (afternoon sample). We tested for differences in estimated cortisol levels between the different timepoints and found a significant decline between estimated morning and midday intercepts (morning $M=.18 \mu \mathrm{g} / \mathrm{dl}$, SE.005; midday $M=.14 \mu \mathrm{g} / \mathrm{dl}, \mathrm{SE} .004$ ), $p<.001$, and between midday and afternoon intercepts (afternoon $M=.10 \mu \mathrm{g} / \mathrm{dl}$, SE.003), $p<.001$

\section{3 | Moderation analysis}

We examined unique contributions of diurnal cortisol pattern and home environment factors to children's negative lability and positive regulation, and the interactions between home environment factors and cortisol pattern, controlling for child age, sex, race/ethnicity, mothers' education, and family structure.

The routine model included morning cortisol intercept, cortisol slope, family routine, and the interactions of cortisol parameters and

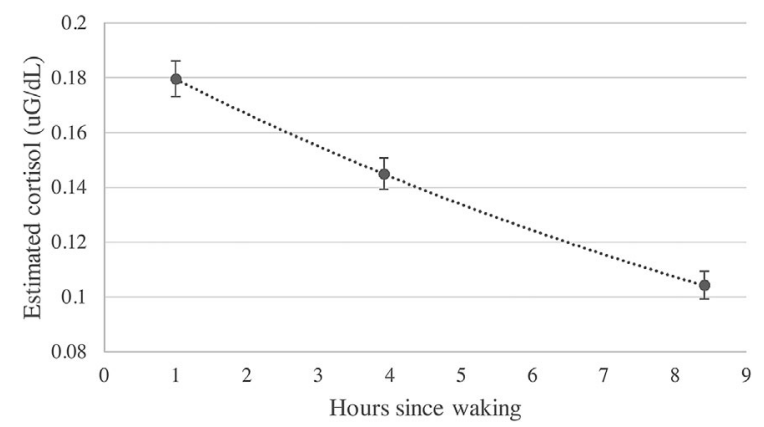

FIGURE 1 Estimated cortisol intercepts across the day. Error bars represent confidence intervals for each timepoint family routine (adjusted for covariates). It had a good fit to the data, $\chi^{2}$ (33) $=38.47, p=.24, \mathrm{CFI}=.98, \mathrm{RMSEA}=.02, \mathrm{Cl}=.00-.05$ (Table 2). Lower levels of routine and lower morning cortisol intercept were associated with higher negative lability ( $14 \%$ of total variance explained), and there was a significant interaction between morning cortisol intercept and routine. The simple slope analysis (Figure 2) revealed that for children with a low morning cortisol intercept, lower routine was related to higher negative lability $(b=-.03$, se $=.01$, $t=-4.39, p<.001)$. Routine was only marginally related to negative lability for children with a high morning cortisol intercept $(b=-.01$, $s e=.01, t=-1.80, p<.10)$. Higher routine, higher morning cortisol intercept, and steeper cortisol slope (indicated by lower value of slope) were related to higher positive regulation ( $16 \%$ of total variance explained). The interaction between morning cortisol intercept and routine was also significant. The simple slope analysis (Figure 3) showed that lower routine was associated with lower positive regulation more strongly in children with a lower morning cortisol intercept $(b=.03, s e=.01, t=5.31, p<.001)$ compared to children with a higher morning cortisol intercept $(b=.01, s e=.005, t=2.39, p<.05)$.

The chaos model included morning cortisol intercept, cortisol slope, home chaos, and the interactions of cortisol pattern and home chaos (adjusted for covariates) and also had a good fit to the data, $\chi^{2}$ $(33)=49.91, p=.03 ; \mathrm{CFI}=.94 ; \mathrm{RMSEA}=.04 ; \mathrm{Cl}=.01-.06$ (Table 3). Greater home chaos predicted higher negative lability (19\% of total variance explained), whereas lower home chaos predicted higher positive regulation ( $17 \%$ of total variance explained). None of the interactions between cortisol and chaos predicted negative lability or positive regulation.

To examine whether findings were due to morning cortisol intercept or cortisol values across the day, we also re-ran each model 
TABLE 2 Interaction of cortisol and routines predicting negative lability and positive regulation

\begin{tabular}{|lrrr|}
\hline & $\boldsymbol{\beta}$ & $\boldsymbol{t}$ & $\boldsymbol{p}$ \\
\hline Negative lability $(\mathrm{N}=380)$ & & & \\
\hline Morning cortisol intercept & -.12 & -2.36 & .02 \\
\hline Cortisol slope & .03 & 0.79 & .43 \\
\hline Routines & -.24 & -4.97 & .00 \\
\hline Morning cortisol intercept $\times$ routines & .11 & 2.02 & .04 \\
\hline Cortisol slope $\times$ routines & -.06 & -1.06 & .29 \\
\hline Positive regulation $(N=380)$ & & & \\
\hline Morning cortisol intercept & .13 & 2.67 & .01 \\
\hline Cortisol slope & -.10 & -1.98 & .04 \\
\hline Routines & .29 & 5.95 & .00 \\
\hline Morning cortisol intercept $\times$ routines & -.12 & -2.29 & .02 \\
\hline Cortisol slope $\times$ routines & .05 & 1.01 & .31 \\
\hline
\end{tabular}

$\chi^{2}(33)=38.47, p=.24 ; \mathrm{CFI}=.98 ; \mathrm{RMSEA}=.02 ; \mathrm{Cl}=.00-.05$. Child age, sex, race/ethnicity, maternal education, and family structure are included in the models.

to investigate whether morning cortisol level specifically or cortisol intercept at other time points (midday or afternoon) predicted emotion regulation outcomes. We found that the main effects and interactions with the intercept at other time points (midday and afternoon) were almost identical to the original results with the morning intercept. Thus, although it makes sense physiologically to model the intercept as the morning cortisol level when characterizing the diurnal cortisol pattern, low cortisol level across the day appears to be driving the finding.

Finally, although children were nested within classrooms, we had classroom data only for a subset $(n=330)$. We used MPlus software version 6.1 (Muthén \& Muthén, 1998-2012) to run all models accounting for clustering by classroom on the subset of the sample with classroom data and again without clustering on the subset of 330 children. The pattern of findings was unchanged (see Supplementary Materials for Tables 4 and 5 with clustered results).

\section{8 | DISCUSSION}

The current study examined positive and negative aspects of environmental influence (home chaos and family routines) in relation to two aspects of emotion regulation (negative lability and positive regulation) in low-income children, and tested cortisol parameters as moderators of these associations. There were associations in expected directions among cortisol parameters (morning level and daily decline), home environment factors, and child emotion regulation outcomes. Home chaos was associated with poor emotion regulation-both greater negative lability and less positive regulation-for all children regardless of diurnal cortisol profile. Child cortisol level moderated the association between family routines and child emotion regulation such that the lack of regular routines was most strongly associated with poorer emotion regulation outcomes among children with lower cortisol levels across the day. Results contribute to a growing literature and increasing recognition of understanding and modeling how stress biology may moderate child response to environmental inputs and also emphasize the need to consider both positive and negative aspects of the home environment in such models.

The main effect of chaos on child emotion regulation was negative and powerful regardless of child stress biology. Exposure to chaos and other stressors associated with poverty can exert a lasting influence by affecting multiple behavioral and brain pathways and biological systems that undergo rapid development early in life, are vital for long-term functioning, and likely influence emotion regulation (Charmandari, Kino, Souvatzoglou, \& Chrousos, 2003; Nelson, 2013). Our finding that chaos was associated with greater negative lability and poorer positive regulation is consistent with prior literature examining chaotic home environments and child emotions, which suggests that growing up in a chaotic home may compromise the development of effective emotion regulation skills (Coley et al., 2015; Deater-Deckard et al., 2009; Fiese \& Winter, 2010; Valiente, LemeryChalfant, \& Reiser, 2007). Specifically, a chaotic household may increase a child's negative lability by presenting frequent emotion regulation challenges under conditions of uncertainty, resulting in the child expressing high-intensity negative affect or frustration in

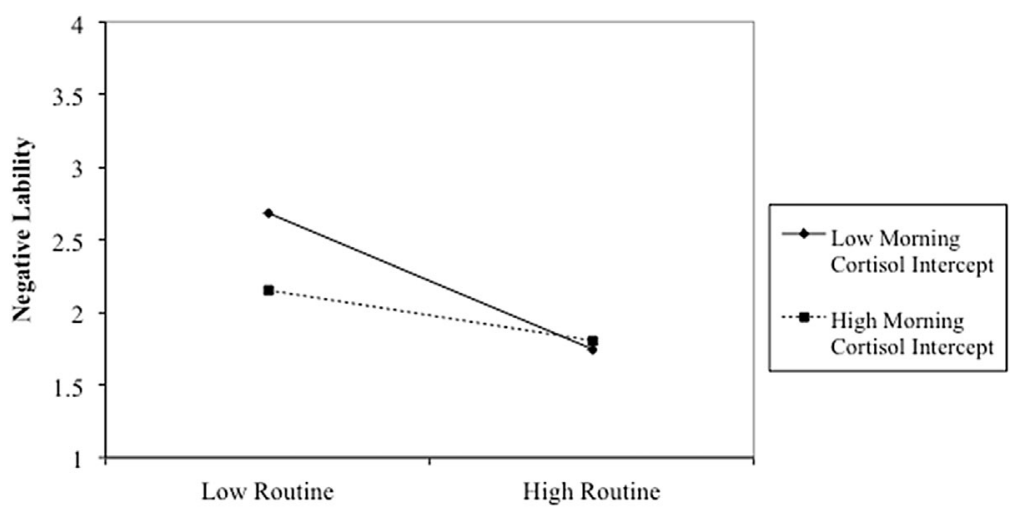

FIGURE 2 Interaction of morning cortisol intercept and routine on negative lability. The slope for low cortisol intercept (solid line) is significantly different from zero, $b=-.03(.01), t=-4.39, p<.001$, but the slope for high intercept (dashed line) is only marginally significant, $b=-.01(.01), t=-1.80, p<.10$ 


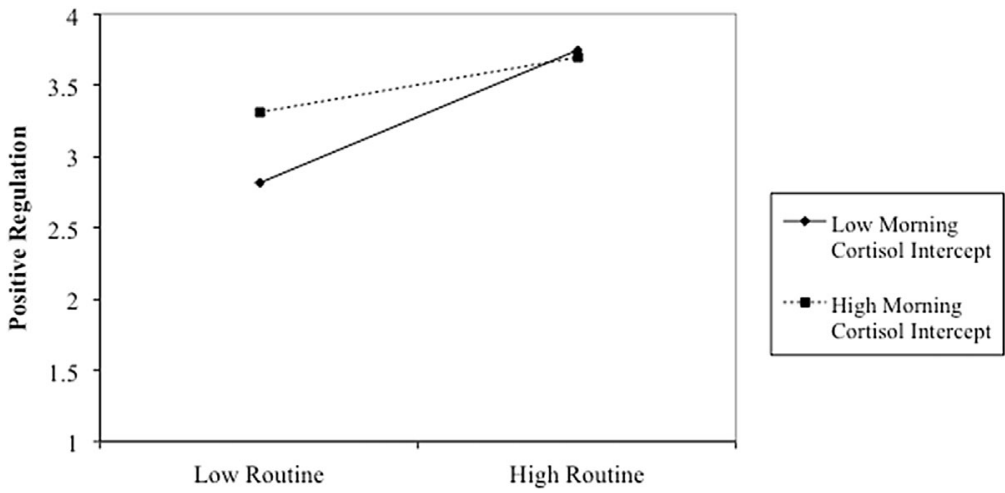

FIGURE 3 Interaction of morning cortisol intercept and routine on positive regulation. Both slopes for low and high cortisol intercept are significantly different from zero, but the slope for low intercept (solid line), $b=.03(01), t=5.31, p<.001$, is steeper than the slope for high intercept (dashed line), $b=.01$ (.005), $t=2.39, p<.05$

response to any given event in order to be noticed and/or due to a lack of information about what to anticipate next. As well, a chaotic household may offer limited opportunities to practice positive regulation skills, which develop optimally under predictable circumstances that allow a child to anticipate challenges and generate emotional responses that are appropriate to the situation, particularly when they do involve negative affect or frustration. Poorer child cognitive and verbal skills, which are important for positive regulation as they underlie many effective emotion regulation strategies such as understanding others' emotions have also been found in association with household chaos (Johnson, Martin, Brooks-Gunn, \& Petrill, 2008; Petrill, Pike, Price, \& Plomin, 2004). In addition to the direct effects on child functioning, parent effortful control (Valiente et al., 2007) and executive functioning skills (Deater-Deckard, Wang, Chen, \& Bell, 2012) have been proposed as indirect pathways through which chaos may affect child emotion regulation. Raising young children is challenging under the best of conditions; understanding that poverty increases cognitive load and can impair executive functioning in adults

TABLE 3 Main effect of chaos predicting negative lability and positive regulation

\begin{tabular}{|lccc|}
\hline & $\boldsymbol{\beta}$ & $\boldsymbol{t}$ & $\boldsymbol{p}$ \\
\hline Negative lability $(\mathrm{N}=380)$ & & & \\
\hline Morning cortisol intercept & -.06 & -1.21 & .23 \\
\hline Cortisol slope & -.01 & -0.37 & .71 \\
\hline Chaos & .36 & 7.55 & .00 \\
\hline Morning cortisol intercept $\times$ chaos & .003 & 0.02 & .99 \\
\hline Cortisol slope $\times$ chaos & .01 & 0.35 & .73 \\
\hline Positive regulation $(N=380)$ & & & \\
\hline Morning cortisol intercept & .04 & 1.60 & .11 \\
\hline Cortisol slope & -.08 & -1.13 & .26 \\
\hline Chaos & -.26 & -6.28 & .00 \\
\hline Morning cortisol intercept $\times$ chaos & -.04 & -0.46 & .64 \\
\hline Cortisol slope $\times$ chaos & -.05 & -1.42 & .16 \\
\hline
\end{tabular}

$\chi^{2}(33)=49.91, p=.03 ; \mathrm{CFI}=.94 ; \mathrm{RMSEA}=.04 ; \mathrm{Cl}=.01-.06$. Child age, sex, race/ethnicity, maternal education, and family structure are included in the models. and children (Mani, Mullainathan, Shafir, \& Zhao, 2013) provides a context for the multiple burdens faced by low-income parents attempting to manage emotion socialization in their young children. Articulating how chaos may influence both child and parent functioning is an important direction for future work.

In contrast to chaos, associations between family routines and child emotion regulation outcomes were moderated by child cortisol level. Among children with a low cortisol level, lack of family routines was associated with poorer emotion regulation outcomes, whereas the presence of family routines was associated with greater positive emotion regulation capacity and less negative lability for these children. Low cortisol has been found in children with stressful caregiving histories and may occur as a result of poor or limited early co-regulation of challenging emotional experiences (Badanes et al., 2011; Gunnar \& Vazquez, 2006). The current study further suggests that at least during the preschool years, household chaos is associated with low cortisol level and that the quality of family routines matters for children with this profile in terms of their emotion regulation outcomes. Results are generally consistent with prior findings that routines were associated with positive child emotion regulation in a large study of low-income families (ZajicekFarber et al., 2012), and also with research suggesting that child factors may drive the effectiveness of and/or need for routines. For example, routines were associated with fewer internalizing behavior problems primarily for children who experienced high daily hassles (Bridley \& Jordan, 2012), and bedtime routines were associated with fewer sleep problems among children who had a more difficult compared to an easier temperament (Wilson et al., 2014). The current study extends such findings by identifying a biological profile -low cortisol level-that may signal high allostatic load as a result of prior stress exposure (Badanes et al., 2011) and may also shape child response to routines. Particularly for children whose LHPA axes secrete less cortisol, structured routines may be necessary to promote emotion regulation capacities. Regular routines may help such children learn how to control negative behavioral outbursts and manage their emotions in productive ways by reducing uncertainty in the environment and providing clear expectations for behavior (Ferretti \& Bub, 2014). 
The current study found different patterns of association between positive and negative aspects of the home environment and child functioning. Routines and chaos may operate somewhat differently in part due to the role of caregiving relationships. Supportive social relationships that provide a predictable structure are essential for effective biological stress regulation (Gunnar \& Donzella, 2002; Strüber et al., 2014). Routines as measured in the current study are characterized by the regularity of such one-on-one interactions with a caregiver, often in the context of a bedtime or other activity that can involve caring engagement or at least attention, as well as general expectations for behavior such as age-appropriate chores (e.g., putting toys away) (Jordan, 2003). Routines may, therefore, function to reduce negative lability by providing a calming context, and foster positive regulation skills (e.g., using emotion words to express feelings) by offering opportunities for the child to talk with the caregiver or see examples of regulation (e.g., in storybooks). In contrast, chaos represents a general level of disorganization, noise, and crowding at a household level that may reflect processes outside of the caregiving relationship (and possibly out of the caregiver's control). Routines and chaos were negatively correlated but only moderately so, suggesting these constructs capture different aspects of home environment. Thus, finding ways to regularly engage in routine parent-child interactions even in the context of chaos may benefit children. For example, in the context of environments that present significant challenges to carve out time/space to read, establishing predictable routines focused on brief greeting and departure or bedtime rituals may be most beneficial. If children who are physiologically underaroused are difficult to engage in routines, their parents may need additional support to tailor routines to meet child needs (Henderson et al., 2011; Spagnola \& Fiese, 2007). Yet, it may be particularly important to make these efforts in order to foster positive emotion regulation outcomes for these children (Strüber et al., 2014). As this physiological pattern may have emerged as a short-term adaptation to stress (Badanes et al., 2011), children with this profile who are not exposed to routines in the family context could experience increased emotion regulation difficulties over time as they enter new social settings, for example, when interacting with preschool peers.

Finally, the current study considered both negative lability and positive regulation as aspects of emotion regulation. Negative lability indicates an inflexibility in emotion expression and dysregulation in mood, which can create difficulties when a child is facing challenge (Kim-Spoon et al., 2013). Positive regulation, on the other hand, reflects how well children engage with others and express situationally appropriate affect, emotional awareness, and empathy, skills that are essential for developing broader social competence (Shields \& Cicchetti, 1997). Although these two components are often negatively correlated with each other ( $r=-.44$ in the current study), both are important and must work in tandem for effective emotion regulation in new settings. Negative lability and positive regulation can have different implications for children's social interactions with peers. For example, children who are highly labile may have a strong emotional reaction to a mild peer stimulus (e.g., an accidental knocking-down of a block tower). Such a child who has practiced positive emotion regulation strategies may be able to appropriately express his or her frustration using words, whereas a child with fewer positive regulation skills may engage in aggression and the event could become a larger conflict. In contrast, although children who are less labile may not enter into as many overt conflicts, if they also lack positive regulation skills they may miss out on opportunities to practice peer negotiation, which is important for building empathy and perspective-taking capacity (Ashiabi, 2007). Positive emotion regulation strategies are a key mediator of associations between early stress exposure and later functioning (Kim et al., 2013; Liberzon et al., 2015). Early emotion regulation difficulties (most often, difficulties with negative lability) are associated with later behavior problems (Hill, Degnan, Calkins, \& Keane, 2006) and can impede school readiness (Graziano, Reavis, Keane, \& Calkins, 2007; Ursache, Blair, \& Raver, 2012). Promoting emotion regulation skills in both areas can therefore benefit children throughout development.

\section{9 | LIMITATIONS}

As with all studies, ours had limitations. The sample was a low-income group of preschool children attending Head Start, so findings may not generalize to all preschool-aged children and families. It is equally important to note that this sample was also not in extreme poverty from a global perspective (e.g., less than $\$ 1.25$ per day), nor was it selected as a sample with an extreme-deprivation or abuse history. The sample was drawn from towns in the rural and "rust belt" Midwest United States, and families where a parent had completed a college degree were excluded. Therefore, although there was a range of race/ ethnicity and family structure among the participants, on average these families were facing notable adversity with regard to income and available opportunity structures in their communities. Our range of home environments may thus also have been somewhat constrained given that poverty can be associated with chaos and instability, so we may not have been able to detect a full range of possible promotive influences. It is important to note that chaos, routines, and emotion regulation were measured using parent report, thus some associations may be inflated due to shared method variance. Using direct assessments of child emotion regulation or observations of home environment would be helpful. We did not measure other cortisol parameters such as the awakening response or evening levels, and thus only captured a portion of the diurnal rhythm. As well, given that the morning cortisol sample was collected upon arrival to school, this sample may have reflected the home environment more directly than the other samples. Cortisol levels at home can differ from cortisol levels at school and the cortisol parameters in the current study may reflect both home and school influences. However, as we did not have measures of classroom environment quality, which may influence both cortisol and emotion regulation, we cannot articulate the nature of such potential associations in this study. Finally, these data were crosssectional and thus it is not possible to draw causal inferences regarding directional effects. Given that there are likely bidirectional associations between home environment, cortisol, and emotion regulation, longitudinal as well as experimental work (e.g., interventions) would be an important next step. 


\section{CONCLUSION}

Poverty affects approximately one in five children in the United States (Jiang, Ekono, \& Skinner, 2013) and can have a lasting negative impact on child development. Identifying how individual differences in child biological stress regulation interact with home environmental factors in the context of poverty informs our understanding of emotion regulation development under conditions of risk. Both home chaos and family routines may shape child emotion regulation, and routines may be particularly important for children with altered stress biology. Assessing how biology may shape response to environmental influences is an important step in determining how best to foster positive emotion regulation outcomes for children.

Disclosures: The authors have no disclosures or other conflicts of interest to report.

\section{REFERENCES}

Ackerman, B. P., \& Brown, E. D. (2010). Physical and psychosocial turmoil in the home and cognitive development. In G. W. Evans, \& T. D. Wachs (Eds.), Chaos and its influence on children's development: An ecological perspective (pp. 35-47). Washington, DC, US: American Psychological Association.

Aiken, L. S., West, S. G., \& Reno, R. R. (1991). Multiple regression: Testing and interpreting interactions. Sage publications, Thousand Oaks, CA.

Anderson, S. E., \& Whitaker, R. C. (2010). Household routines and obesity in US preschool-aged children. Pediatrics, 125, 420-428. DOI: 10.1542/ peds.2009-0417

Arbuckle, J. L. (2013). IBM SPSS Amos 22 user's guide. Crawfordville, FL: Amos Development Corporation.

Ashiabi, G. S. (2007). Play in the preschool classroom: Its socioemotional significance and the teacher's role in play. Early Childhood Education Journal, 35, 199-207. DOI: 10.1007/s10643-007-0165-8

Badanes, L. S., Watamura, S. E., \& Hankin, B. L. (2011). Hypocortisolism as a potential marker of allostatic load in children: Associations with family risk and internalizing disorders. Developmental Psychopathology, 23, 881-896. DOI: 10.1017/s095457941100037x

Bernard, K., Butzin-Dozier, Z., Rittenhouse, J., \& Dozier, M. (2010). Cortisol production patterns in young children living with birth parents vs children placed in foster care following involvement of child protective services. Archives of Pediatrics \& Adolescent Medicine, 164, 438-443. DOI: 10.1001/archpediatrics.2010.54

Bernard, K., Hostinar, C. E., \& Dozier, M. (2015). Intervention effects on diurnal cortisol rhythms of Child Protective Services-referred infants in early childhood: Preschool follow-up results of a randomized clinical trial. JAMA Pediatrics, 169, 112-119.

Bernard, K., Zwerling, J., \& Dozier, M. (2015). Effects of early adversity on young children's diurnal cortisol rhythms and externalizing behavior. Developmental Psychobiology, 57, 935-947. DOI: 10.1002/dev.21324

Blair, C., Granger, D., \& Peters Razza, R. (2005). Cortisol reactivity is positively related to executive function in preschool children attending Head Start. Child Development, 76, 554-567.

Blair, C., Raver, C. C., Granger, D., Mills-Koonce, R., \& Hibel, L. (2011). Allostasis and allostatic load in the context of poverty in early childhood. Developmental Psychopathology, 23, 845-857. DOl: $10.1017 / \mathrm{s} 0954579411000344$

Bridley, A., \& Jordan, S. S. (2012). Child routines moderate daily hassles and children's psychological adjustment. Children's Health Care, 41, 129-144. DOI: 10.1080/02739615.2012.657040
Bruce, J., Fisher, P. A., Pears, K. C., \& Levine, S. (2009). Morning cortisol levels in preschool-aged foster children: Differential effects of maltreatment type. Developmental Psychobiology, 51, 14-23. DOI: $10.1002 /$ dev. 20333

Buckley, T. M., \& Schatzberg, A. F. (2005). On the interactions of the hypothalamic-pituitary-adrenal (HPA) axis and sleep: Normal HPA axis activity and circadian rhythm, exemplary sleep disorders. The Journal of Clinical Endocrinology \& Metabolism, 90, 3106-3114. DOI: 10.1210/ jc.2004-1056

Charmandari, E., Kino, T., Souvatzoglou, E., \& Chrousos, G. P. (2003). Pediatric stress: Hormonal mediators and human development. Hormone Research, 59, 161-179.

Chen, E., Cohen, S., \& Miller, G. E. (2010). How low socioeconomic status affects 2-year hormonal trajectories in children. Psychological Science, 21, 31-37. DOI: 10.1177/0956797609355566

Chrousos, G. P., \& Gold, P. W. (1992). The concepts of stress and stress system disorders: Overview of physical and behavioral homeostasis. JAMA, 267, 1244-1252. DOI: 10.1001/jama.1992.03480090092034

Churchill, S. L., \& Stoneman, Z. (2004). Correlates of family routines in Head Start families. Early Childhood Research and Practice, 6, 1-15. Available online at: http://ecrp.uiuc.edu/v6n1/churchill.html

Cole, P. M., Martin, S. E., \& Dennis, T. A. (2004). Emotion regulation as a scientific construct: Methodological challenges and directions for child development research. Child Development, 75, 317-333. DOI: 10.1111/j.1467-8624.2004.00673.x

Coley, R. L., Lynch, A. D., \& Kull, M. (2015). Early exposure to environmental chaos and children's physical and mental health. Early Childhood Research Quarterly, 32, 94-104.

de Kloet, E. R., Oitzl, M. S., \& Joels, M. (1999). Stress and cognition: Are corticosteroids good or bad guys? Trends in Neurosciences, 22 422-426.

Deater-Deckard, K., Mullineaux, P. Y., Beekman, C., Petrill, S. A., Schatschneider, C., \& Thompson, L. A. (2009). Conduct problems, IQ, and household chaos: A longitudinal multi-informant study. Journal of Child Psychology and Psychiatry, 50, 1301-1308. DOI: 10.1111/j.14697610.2009.02108.x

Deater-Deckard, K., Wang, Z., Chen, N., \& Bell, M. A. (2012). Maternal executive function, harsh parenting, and child conduct problems. Journal of Child Psychology and Psychiatry, 53, 1084-1091. DOI: 10.1111/j.1469-7610.2012.02582.x

Erickson, K., Drevets, W., \& Schulkin, J. (2003). Glucocorticoid regulation of diverse cognitive functions in normal and pathological emotional states. Neuroscience Biobehavioral Reviews, 27, 233-246.

Evans, G. W., \& English, K. (2002). The environment of poverty: Multiple stressor exposure, psychophysiological stress, and socioemotional adjustment. Child Development, 73, 1238-1248. DOI: 10.1111/14678624.00469

Ferretti, L. K., \& Bub, K. L. (2014). The influence of family routines on the resilience of low-income preschoolers. Journal of Applied Developmental Psychology, 35, 168-180.

Fiese, B. H., \& Winter, M. A. (2010). The dynamics of family chaos and its relation to children's socioemotional well-being. In G. W. Evans, \& T. D. Wachs (Eds.), Chaos and its influence on children's development: An ecological perspective (pp. 49-66). Washington, DC, US: American Psychological Association.

Graziano, P. A., Reavis, R. D., Keane, S. P., \& Calkins, S. D. (2007). The role of emotion regulation and children's early academic success. Journal of School Psychology, 45, 3-19. DOI: 10.1016/j.jsp.2006.09.002

Gross, J. J., \& John, O. P. (2003). Individual differences in two emotion regulation processes: Implications for affect, relationships, and wellbeing. Journal of Personality and Social Psychology, 85, 348-362. 
Gunnar, M. R., \& Donzella, B. (2002). Social regulation of the cortisol levels in early human development. Psychoneuroendocrinology, 27, 199-220.

Gunnar, M. R., Tout, K., de Haan, M., Pierce, S., \& Stansbury, K. (1997). Temperament, social competence, and adrenocortical activity in preschoolers. Developmental Psychobiology, 31, 65-85.

Gunnar, M. R., \& Vazquez, D. M. (2001). Low cortisol and a flattening of expected daytime rhythm: Potential indices of risk in human development. Development and Psychopathology, 13, 515-538.

Gunnar, M. R., \& Vazquez, D. M. (2006). Stress neurobiology and developmental psychopathology. Developmental Psychopathology, 2, 533-577.

Hardaway, C. R., Wilson, M. N., Shaw, D. S., \& Dishion, T. J. (2012). Family functioning and externalizing behaviour among low-income children: Self-regulation as a mediator. Infant and Child Development, 21, 67-84. DOI: $10.1002 /$ icd.765

Hart, J., Gunnar, M. R., \& Cicchetti, D. (1995). Salivary cortisol in maltreated children: Evidence of relations between neuroendocrine activity and social competence. Development and Psychopathology, 7, 11-26. DOI: $10.1017 /$ S0954579400006313

Heim, C., Ehlert, U., \& Hellhammer, D. H. (2000). The potential role of hypocortisolism in the pathophysiology of stress-related bodily disorders. Psychoneuroendocrinology, 25, 1-35.

Henderson, J. A., Barry, T. D., Bader, S. H., \& Jordan, S. S. (2011). The relation among sleep, routines, and externalizing behavior in children with an autism spectrum disorder. Research in Autism Spectrum Disorders, 5, 758-767.

Hill, A. L., Degnan, K. A., Calkins, S. D., \& Keane, S. P. (2006). Profiles of externalizing behavior problems for boys and girls across preschool: The roles of emotion regulation and inattention. Developmental Psychology, 42, 913-928. DOI: 10.1037/0012-1649.42.5.913

Hruschka, D. J., Kohrt, B. A., \& Worthman, C. M. (2005). Estimating between- and within-individual variation in cortisol levels using multilevel models. Psychoneuroendocrinology, 30, 698-714.

Hu, L. t., \& Bentler, P. M. (1999). Cutoff criteria for fit indexes in covariance structure analysis: Conventional criteria versus new alternatives. Structural Equation Modeling: A Multidisciplinary Journal, 6, 1-55. DOI: 10.1080/10705519909540118

Jiang, Y., Ekono, M., \& Skinner, C. (2013). Basic Facts About Low-Income Children under 18 Years, 2013. National Center for Children in Poverty, Columbia University Mailman School of Public Health.

Johnson, A. D., Martin, A., Brooks-Gunn, J., \& Petrill, S. A. (2008). Order in the house! associations among household chaos, the home literacy environment, maternal reading ability, and children's early reading. Merrill-Palmer Quarterly, 54, 445-472. Available online at: https:// muse.jhu.edu/journals/merrill-palmer_quarterly/v054/54.4.johnson. html

Jordan, S. S. (2003). Further validation of the Child Routines Inventory (CRI): Relationship to parenting practices, maternal distress and child externalizing behavior. Louisiana State University (Unpublished).

Kim-Spoon, J., Cicchetti, D., \& Rogosch, F. A. (2013). A longitudinal study of emotion regulation, emotion lability-negativity, and internalizing symptomatology in maltreated and nonmaltreated children. Child Development, 84, 512-527. DOI: 10.1111/j.1467-8624.2012.01857.x

Kim, P., Evans, G. W., Angstadt, M., Ho, S. S., Sripada, C. S., Swain, J. E., \& Phan, K. L. (2013). Effects of childhood poverty and chronic stress on emotion regulatory brain function in adulthood. Proceedings of the National Academy of Sciences, 110, 18442-18447. DOI: 10.1073/ pnas.1308240110

Kushner, M. R., Barrios, C., Smith, V. C., \& Dougherty, L. R. (2015). Physiological and behavioral vulnerability markers increase risk to early life stress in preschool-aged children. Journal of Abnormal Child Psychology, 44, 1-12. DOI: 10.1007/s10802-015-0087-7
Laurent, H. K., Leve, L. D., Neiderhiser, J. M., Natsuaki, M. N., Shaw, D. S., Fisher, P. A., \& Reiss, D. (2013). Effects of parental depressive symptoms on child adjustment moderated by HPA: Within- and between-family risk. Child Development, 84, 528-542. DOI: 10.1111/ j.1467-8624.2012.01859.x

Liberzon, I., Ma, S. T., Okada, G., Shaun Ho, S., Swain, J. E., \& Evans, G. W. (2015). Childhood poverty and recruitment of adult emotion regulatory neurocircuitry. Social Cognitive and Affective Neuroscience. 10, 1596-1606. DOI: 10.1093/scan/nsv045

Little, R. J. A. (1988). A test of missing completely at random for multivariate data with missing values. Journal of the American Statistical Association, 83, 1198-1202. DOI: 10.2307/2290157

Lumeng, J. C., Miller, A., Peterson, K. E., Kaciroti, N., Sturza, J., Rosenblum, K., \& Vazquez, D. M. (2014). Diurnal cortisol pattern, eating behaviors and overweight in low-income preschool-aged children. Appetite, 73, 65-72. DOI: 10.1016/j.appet.2013.10.016

Mani, A., Mullainathan, S., Shafir, E., \& Zhao, J. (2013). Poverty impedes cognitive function. Science, 341, 976-980. DOI: 10.1126/ science.1238041

Matheny, A. P., Wachs, T. D., Ludwig, J. L., \& Phillips, K. (1995). Bringing order out of chaos: Psychometric characteristics of the confusion, hubbub, and order scale. Journal of Applied Developmental Psychology, 16, 429-444.

Miller, A. L., Fine, S. E., Kiely Gouley, K., Seifer, R., Dickstein, S., \& Shields, A. (2006). Showing and telling about emotions: Interrelations between facets of emotional competence and associations with classroom adjustment in Head Start preschoolers. Cognition and Emotion, 20, 1170-1192. DOI: 10.1080/02699930500405691

Miller, G. E., Chen, E., \& Parker, K. J. (2011). Psychological stress in childhood and susceptibility to the chronic diseases of aging: Moving toward a model of behavioral and biological mechanisms. Psychological Bulletin, 137, 959.

Miller, G. E., Chen, E., \& Zhou, E. S. (2007). If it goes up, must it come down? Chronic stress and the hypothalamic-pituitary-adrenocortical axis in humans. Psychological Bulletin, 133, 25-45.

Morgan, J. K., Shaw, D. S., \& Olino, T. M. (2012). Differential susceptibility effects: The interaction of negative emotionality and sibling relationship quality on childhood internalizing problems and social skills. Journal of Abnormal Child Psychology, 40, 885-899. DOI: 10.1007/s10802012-9618-7

Muthén, L. K., \& Muthén, B.O. (1998-2012). Mplus User's Guide (7th ed.). Los Angeles, CA: Muthén \& Muthén.

Nelson, C. A. (2013). Blological embedding of early life adversity. JAMA Pediatrics, 167, 1098-1100. DOI: 10.1001/jamapediatrics.2013.3768

Nicolaides, N. C., Kyratzi, E., Lamprokostopoulou, A., Chrousos, G. P., \& Charmandari, E. (2015). Stress, the stress system and the role of glucocorticoids. Neuroimmunomodulation, 22, 6-19. Available online at: http://www.karger.com/DOl/10.1159/000362736

Osborne, C., \& McLanahan, S. (2007). Partnership instability and child wellbeing. Journal of Marriage and Family, 69, 1065-1083. DOI: 10.1111/ j.1741-3737.2007.00431.x

Perry, N. B., Mackler, J. S., Calkins, S. D., \& Keane, S. P. (2014). A transactional analysis of the relation between maternal sensitivity and child vagal regulation. Developmental Psychology, 50, 784-793. DOI: $10.1037 / \mathrm{a} 0033819$

Petrill, S. A., Pike, A., Price, T., \& Plomin, R. (2004). Chaos in the home and socioeconomic status are associated with cognitive development in early childhood: Environmental mediators identified in a genetic design. Intelligence, 32, 445-460.

Shields, A., \& Cicchetti, D. (1997). Emotion regulation among school-age children: The development and validation of a new criterion Q-sort scale. Developmental Psychology, 33, 906. 
Shonkoff, J. P., Garner, A. S., Siegel, B. S., Dobbins, M. I., Earls, M. F., Garner, A. S., $\&$ Wood, D. L. (2012). The lifelong effects of early childhood adversity and toxic stress. Pediatrics, 129, e232-e246. DOI: 10.1542/peds.2011-2663

Spagnola, M., \& Fiese, B. H. (2007). Family routines and rituals: A context for development in the lives of young children. Infants \& Young Children, 20, 284-299. DOI: 10.1097/01.IYC.0000290352.32170.5a

Sprunger, L. W., Boyce, W. T., \& Gaines, J. A. (1985). Family-infant congruence: Routines and rhythmicity in family adaptations to a young infant. Child Development, 56, 564-572. DOI: 10.2307/1129746

Strüber, N., Strüber, D., \& Roth, G. (2014). Impact of early adversity on glucocorticoid regulation and later mental disorders. Neuroscience \& Biobehavioral Reviews, 38, 17-37.

Suor, J. H., Sturge-Apple, M. L., Davies, P. T., Cicchetti, D., \& Manning, L. G. (2015). Tracing differential pathways of risk: Associations among family adversity, cortisol, and cognitive functioning in childhood. Child Development, 86, 1142-1158. DOI: 10.1111/cdev.12376

Tyrka, A. R., Lee, J. K., Graber, J. A., Clement, A. M., Kelly, M. M., DeRose, L., \& Brooks-Gunn, J. (2012). Neuroendocrine predictors of emotional and behavioral adjustment in boys: Longitudinal follow-up of a community sample. Psychoneuroendocrinology, 37, 2042-2046.

Ursache, A., Blair, C., \& Raver, C. C. (2012). The promotion of self-regulation as a means of enhancing school readiness and early achievement in children at risk for school failure. Child Development Perspectives, 6, 122-128. DOI: 10.1111/j.1750-8606.2011.00209.x

Valiente, C., Lemery-Chalfant, K., \& Reiser, M. (2007). Pathways to problem behaviors: Chaotic homes, parent and child effortful control, and parenting. Social Development, 16, 249-267. DOI: 10.1111/j.14679507.2007.00383.x

van Goozen, S. H., Fairchild, G., Snoek, H., \& Harold, G. T. (2007). The evidence for a neurobiological model of childhood antisocial behavior. Psychological Bulletin, 133, 149-182.

Wilson, K. E., Lumeng, J. C., Kaciroti, N., Chen, S. Y.-P., LeBourgeois, M. K., Chervin, R. D., \& Miller, A. L. (2014). Sleep hygiene practices and bedtime resistance in low-income preschoolers: Does temperament matter? Behavioral Sleep Medicine, 13, 412-423.

Zajicek-Farber, M. L., Mayer, L. M., \& Daughtery, L. G. (2012). Connections among parental mental health, stress, child routines, and early emotional behavioral regulation of preschool children in low-income families. Journal of the Society for Social Work and Research, 3, 31-50. DOI: $10.5243 /$ jsswr.2012.3

Zalewski, M., Lengua, L. J., Kiff, C. J., \& Fisher, P. A. (2012). Understanding the relation of low income to HPA-axis functioning in preschool children: Cumulative family risk and parenting as pathways to disruptions in cortisol. Child Psychiatry and Human Development, 43, 924-942. DOI: 10.1007/s10578-012-0304-3

Zuckerman, M. (1999). Vulnerability to psychopathology: A biosocial model. American Psychological Association. Washington, DC.

\section{SUPPORTING INFORMATION}

Additional Supporting Information may be found online in the supporting information tab for this article. 